\title{
Injection of Reducing Gas into Blast Furnace (FTG Process)*
}

\author{
By Takeo YATSUZUKA, ${ }^{* *}$ Kazuyuki NAKAYAMA, ${ }^{* *}$ Kazuo OMORI, ${ }^{* *}$ Yoshiaki HARA, ${ }^{* *}$ \\ and Masaaki IGUCHI**
}

\section{Synopsis}

Fuel injection through blast tuyeres is a very effective method to reduce the coke rate, since coke is directly replaced by injected fuel. Recently a coke rate of $360 \mathrm{~kg} / \mathrm{t}$ has been obtained for some blast furnaces by fuel oil injection of approximately $100 \mathrm{~kg} / \mathrm{t}$ in combination with oxygen enrichment. However, the capacity of the raceway as the gasifying chamber to burn the injected fuel from tuyeres is limited. In order to make further saving of coke, it is necessary to produce a reducing gas from fuel oil outside of the furnace and to inject it into the blast furnace.

Reducing gas injection in shaft has been a subject of investigation in blast furnace operation technics, and some reports on this field have been published recently. The authors also have carried out some fundamental studies, such as estimation of the effect of gas injection by means of mathematical model, investigation on reducing gas making process, examination on distribution of injected gas in blast furnace by model, and design of equipments handling hot reducing gas. Concerning the reducing gas making, joint research with Texaco Development Corporation has been conducted.

The authors call this process as Fuji-Texaco-Gasinjection Process (FTG).

A commercial-scale experiment has heen carried out on a blast furnace having an inner volume of $1691 \mathrm{~m}^{3}$. A Texaco type generator having a fuel gasifying capacity of $5 \mathrm{t} / \mathrm{hr}$ was installed. From this experiment the following results were obtained:

(1) The partial oxidation process was considered to be the most suitable process for producing a hot reducing gas from the available fuel oil.

(2) Coke saving was 0.9 to $1.0 \mathrm{~kg}$ per kilogram of the gasified fuel oil when hot reducing gas was injected into the lower part of the shaft of blast furnace under the following conditions:

Rate of fuel oil injected through tuyeres: $70 \mathrm{~kg} / \mathrm{t}$

Rate of fuel oil gasified and injected into shaft: $30 \mathrm{~kg} / \mathrm{t}$

R.R. value of injected gas: 6 to 8 where R.R. $=\left(\mathrm{CO}+\mathrm{H}_{2}\right) /\left(\mathrm{CO}_{2}+\mathrm{H}_{2} \mathrm{O}\right)$

(3) The fuel oil gasifying system and the hot reducing gas handling system were maintained in good condition, and the blast furnace was operated smoothly.

\section{Introduction}

To reduce coke rate in blast furnace process, fuel injection through blast tuyeres is the most effective means, and some blast furnaces have recently achieved coke rates of approximately $360 \mathrm{~kg} / \mathrm{t}$ by fuel oil injections of about $100 \mathrm{~kg} / \mathrm{t}$ combined with oxygen enrichment of blast

However, the quantity of fuel to be injected is limited due to the following reasons:

(1) The temperature of raceway at tuyeres decreases. The theoretically calculated temperature of raceway at tuyeres is generally controlled about $2000^{\circ}$ to $2400^{\circ} \mathrm{C}$. Decrease of raceway temperature caused by fuel oil injection must be compensated by some means such as higher blast temperature or oxygen enrichment of blast.
(2) The decrease of oxygen-to-fuel ratio (theoretically calculated) causes incomplete combustion of fuel and generation of soot. Oxygen-to-fuel ratio expressed in atom-to-atom is one of the most important factors for fuel combustion. Decrease of this figure results in soot generation, decrease of fuel efficiency, and then decrease of coke saving rate by fuel oil, namely replacement ratio of coke by oil in blast furnace performance.

Figure 1 shows the relationship between the oxygento-fuel ratio and replacement ratio of coke by oil in a blast furnace. This figure shows clearly that the replacement ratio decreases sharply as the oxygen-tofuel ratio decreases.

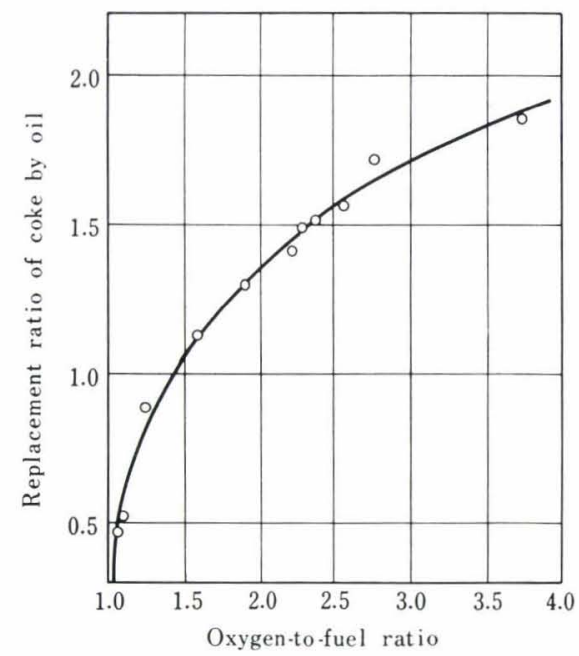

Fig. 1. Relation between oxygen-to-fuel ratio and replacement ratio of coke by oil

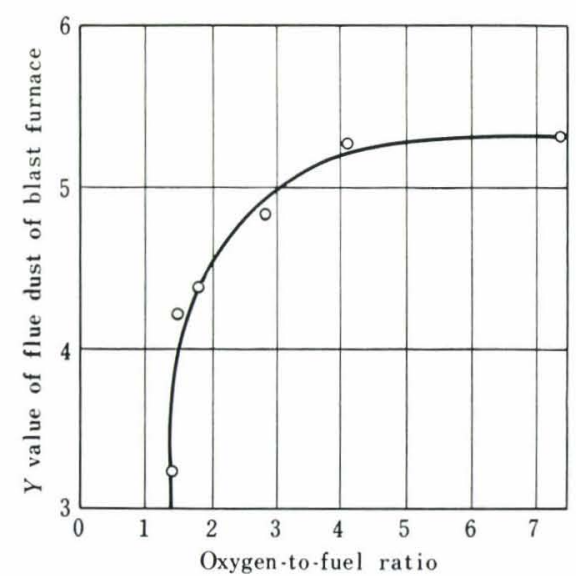

Fig. 2. Relation between oxygen-to-fuel ratio and $Y$ value ${ }^{11}$ of flue dust of blast furnace 
The proportion of soot in flue dust may be expressed by the characteristic value named " $Y$ value. "*1)

Figure 2 shows the relationship between oxygen-tofuel ratio and $Y$ value of flue dust in blast furnace gas washer. It is clear that, as the oxygen-to-fuel ratio decreases to 1.5 or less, the $Y$ value of flue dust decreases and then soot generation increases sharply. As understood from these figures, the burning condition of oil becomes remarkably bad below the oxygento-fuel ratio of 1.5 as the critical point, and furthermore the replacement ratio of coke by oil also lowers sharply at 1.2 or less of oxygen-to-fuel ratio.

At blast consumption of $1300 \mathrm{Nm}^{3}$ per ton of pig iron, for example, soot generation begins to increase at oil injection rate of $75 \mathrm{~kg} / \mathrm{t}$ and decrease of replacement ratio of coke by oil becomes remarkable at $95 \mathrm{~kg} / \mathrm{t}$, although these values may vary depending on the level of blast consumption for hot metal. If fuel rate or blast consumption per ton of pig iron are lowered by some means such as beneficiation of burden or higher blast temperature, this critical point is expected to be further lowered.

After all, the quantity of injected fuel oil depends upon the capacity of the raceway in front of tuyere as oil gasifying chamber. To avoid these problems and get more coke saving, it is usefull to install an oil gasifying chamber outside furnace and inject hot reduing gas into shaft of blast furnace.

With regard to this method, test results from a commercial-scale furnace at Pompey, ${ }^{2)}$ an experimental furnace of U.S. Bureau of Mines, ${ }^{3)}$ and a similar one of Nippon Kokan ${ }^{4}$ have been already published. However, these tests were not carried out for a long time on large furnace.

After fundamental examinations in some years, the authors have conducted commercial-scale experiments on this method since 1970, using a blast furnace with hearth diameter of $9.1 \mathrm{~m}$.

\section{Production of Reducing Gas for Blast Furnace}

Generation of reducing gases is an industrially established technique (in the methanol, chemical fertilizer, and other industries). Industrial processes of producing $\mathrm{CO}$ and $\mathrm{H}_{2}$ from hydrocarbons are classified into (1) partial oxidation processes (Texaco process, Shell process), (2) steam reforming processes (I.C.I. process, TOPSO process, CHEMICO process), and (3) combinations of both processes (G.P. process, Lurgi process, TOPSO-SBA process). Their principles and features are as follows, respectively:

(1) Partial oxidation processes: These are based on a method of cracking the raw material at $1000^{\circ}$ to $1600^{\circ} \mathrm{C}$ with the heat of partial combustion of the raw material with air or oxygen. This method, already used in actual operation at many works, has the features that there is no limit to the kinds of raw materials, the equipment is simple in construction, but much soot is produced, and a large quantity of oxygen is needed to obtain a high purity gas.

(2) Steam reforming processes: These consist of preheating the raw material at $800^{\circ}$ to $1000^{\circ} \mathrm{C}$, adding steam to it, passing the mixed materials through a catalyst layer and cracking the raw material. The raw material must not contain sulfur (catalytic poison). The disadvantage of these methods is that materials containing asphalt such as crude oil, heavy oil, and tar cannot be used, because the carbon deposited from these materials clogs the catalyst layers. The advantages of the methods are that oxygen is not necessary for the cracking and the $\mathrm{H}_{2}$ yield is high.

(3) Combination processes: These consist of preheating the raw material at $300^{\circ}$ to $500^{\circ} \mathrm{C}$, adding steam to it, cracking the raw material by the use of oxygen burners, and passing the mixed material through catalyst layers for perfect cracking. These methods also require the use of raw materials containing little sulfur or asphalt. The quantity of oxygen needed by these methods is relatively small.

In deciding which gasifying process must be adopted, the reducing power of the gas to be generated, namely the $R$ value defined by $\left(\mathrm{CO}+\mathrm{H}_{2}\right) /\left(\mathrm{CO}_{2}+\mathrm{H}_{2} \mathrm{O}\right)$ and the selection of raw material should be taken into consideration. Figure 3 shows the reducing value of the gas inside a blast furnace in the vertical direction. If the $R$ value of the injected reducing gas is lower than the $R$ value of the furnace gas itself at the injection level of the blast furnace, either the reducing action decreases or a carbon solution reaction takes place to consume coke. So it is preferable to inject a reducing gas having an $R$ value higher than the $R$ value of the furnace gas itself at the injecting position. The figure shows that the $R$ value of the furnace gas above the lower part of the shaft is less than five. So the $R$ value of the reducing gas must be five or more. When such a raw material as desulfurized naphtha or natural gas can be obtained easily, steam reforming processes and combination processes are often adopted. However, these are not suited to blast furnaces because they involve the problem that the life of catalyst is short or that the $R$ value is low due to high steam ratio. On the other hand, partial oxidation processes are suited to the present condition of this country because they permit the use of heavy oil and can generate reducing gases having high $R$ values, although they have the drawbacks that the equipment construction cost is

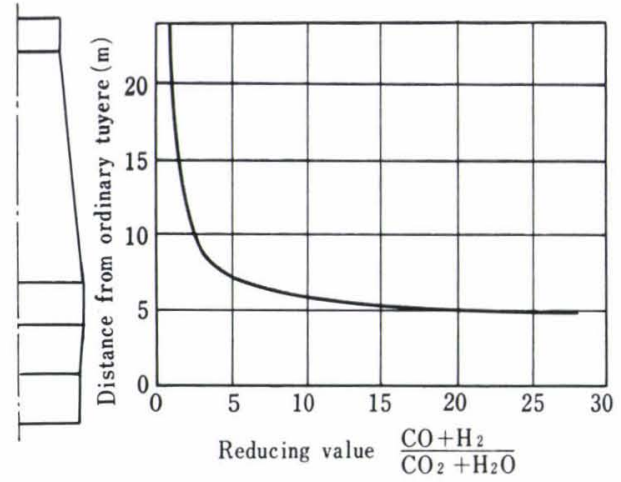

Fig. 3. Reducing value of gas inside blast furnace

* " $Y$ value " is luminocity measureả by a photoelectric spectrophotometer: white is represented by $Y=100$, black by $Y=0$. 


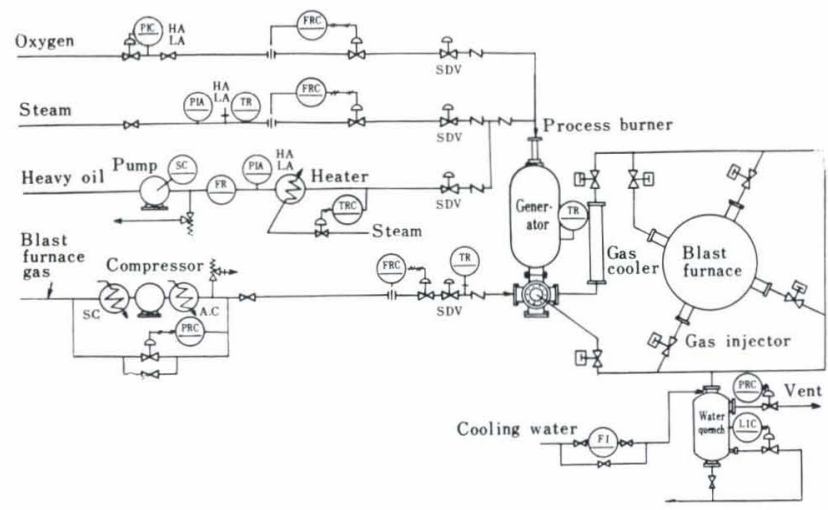

Iron production: $2960 \mathrm{t} /$ day Blast volume: $2650 \mathrm{Nm}^{3} / \mathrm{min}$ Blast temperature: $1020^{\circ} \mathrm{C}$

Fig. 4. Flow sheet of FTG process

a little higher due to the installation of an oxygen plant and that the generation of soot cannot be avoided.

Figure 4 shows the flow sheet of Hirohata FTG test plant. Preheated heavy oil, oxygen, and steam are charged at specified ratio to the cracking burners attached to the reducing gas generator and are gasified at about $1500^{\circ} \mathrm{C}$. The reducing gas permissible for use in blast furnaces must have a high $R$ value and contain little soot. The composition of the gas is determined mostly by the ratio of heavy oil, oxygen, and steam, though influenced more or less by the preheating temperature of the oil and the heat loss from the generator walls. Soot is scarcely produced in the partial oxidation of liquid propane gas (LPG) and liquid natural gas (LNG) but in the case of heavy oil the generation of soot is unavoidable to some extent.

Generally speaking, the $R$ value of reducing gas can be raised by using insufficient quantities of oxygen and steam but this method causes increase of soot generation. Taking these facts into consideration, therefore, the optimum operational conditions must be found for most economical gas generation. If the soot generation increases at a specified oxygen ratio, carbon dioxide increases, causing a decrease in $R$ value, and the furnace temperature becomes abnormally high. The production of soot may be expressed by the following experimental formula:

$$
\log S=K_{1} \cdot(\mathrm{O} / \mathrm{C})+K_{2}
$$

where, $S$ : soot (wt $\%$ for carbon in oil)

$\mathrm{O}:$ oxygen $\left(\mathrm{Nm}^{3} / \mathrm{hr}\right)$

$\mathrm{C}$ : carbon contained in oil ( $\mathrm{kg}-\mathrm{C}$ in oil $/ \mathrm{hr}$ )

$\mathrm{O} / \mathrm{C}$ : oxygen-to-carbon ratio $\left(\mathrm{Nm}^{3}-\mathrm{O}_{2} / \mathrm{kg}-\mathrm{C}\right.$ in oil $)$.

Both $K_{1}$ and $K_{2}$ are constants determined by the inside pressure and the design of the burners and the furnace.

\section{Theoretical Estimation of the Effect of Reduc- ing Gas Injection upon the Furnace Opera- tion}

The effect of reducing gas injection was estimated theoretically in the following order:
Table 1. Chemical reaction considered in mathematical model of blast furnace

(1) Indirect reduction by $\mathrm{CO} \mathrm{CO}+\mathrm{FeO}_{x}=\mathrm{CO}_{2}+\mathrm{FeO}_{x-1}$

(2) Indirect reduction by $\mathrm{H}_{2} \quad \mathrm{H}_{2}+\mathrm{FeO}_{x}=\mathrm{H}_{2} \mathrm{O}+\mathrm{FeO}_{x-1}$

(3) Carbon solution by $\mathrm{CO}_{2} \quad \mathrm{CO}_{2}+\mathrm{C}=2 \mathrm{CO}$

(4) Carbon solution by $\mathrm{H}_{2} \mathrm{O} \quad \mathrm{H}_{2} \mathrm{O}+\mathrm{C}=\mathrm{H}_{2}+\mathrm{CO}$

(5) Direct reduction by $\mathrm{C} \quad \mathrm{C}+\mathrm{FeO}=\mathrm{CO}+\mathrm{Fe}$

(6) Decomposition of lime $\mathrm{CaCO}_{3}=\mathrm{CO}_{2}+\mathrm{CaO}$

(7) Evaporation of absorbed water

(8) Water gas reaction

$\mathrm{H}_{2} \mathrm{O}(l)=\mathrm{H}_{2} \mathrm{O}(\mathrm{g})$

$\mathrm{CO}_{2}+\mathrm{H}_{2}=\mathrm{CO}+\mathrm{H}_{2} \mathrm{O}$

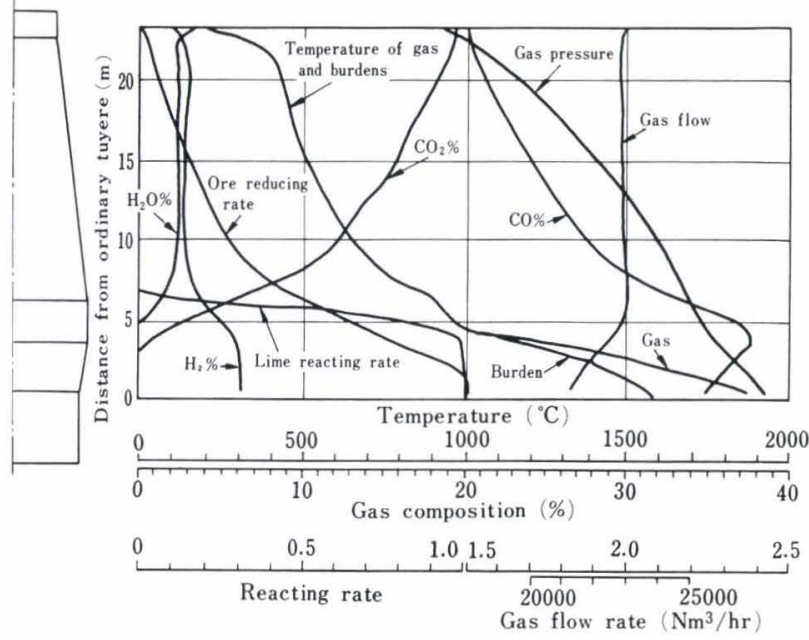

Fig. 5. Analytical results on blast furnace reaction at normal operation

(1) Establishment of a mathematical model of the reaction rates in the furnace.

(2) Calculation of the decrease of coke rate and the increase of pig iron production due to reducing gas injection by using the above mentioned model.

(3) Experimental correction of the model considering the actual mixing and diffusion of reducing gas in the furnace.

1. Calculation of the Effect of Reducing Gas Injection on Blast Furnace Process by Mathematical Model

Some mathematical models for blast furnace process have been already reported. The authors took notice to the eight principal reactions shown in Table 1 out of the many complicated blast furnace reactions and conducted an equational analysis (the model by Dr. Muchi $)^{5-7)}$ of a practical blast furnace, by solving two algebraical equations and nine differential equations for kinetic chemical reaction, heat transfer, heat balance, and material balance. This model, for which data of Hirohata No. 2 blast furnace was used, was prepared on the assumption that the temperatures, compositions, flow rates, and pressures of the gas were uniform in the radial direction and that direct reduction occurred between coke and FeO only. The results of the calculation on the reactions of Hirohata No. 2 blast furnace operated under normal conditions are shown in Fig. 5. The calculated results on ver- 
tical distribution of temperature are compared in Fig. 6 with the actual values measured at Hirohata No. 3 blast furnace and data given in various literatures. Also comparisons with other published analytical results ${ }^{8-10)}$ were made. The authors' calculations agreed relatively well with the literature values in both vertical temperature profile and gas composition profile.

The authors further calculated by using Dr. Muchi's model the effects of the quantity, temperature, and inject position of reducing gas on the decrease of coke rate and the increase of pig iron production, when the reducing gas was injected as the additional fuel at a fixed blast volume operation. This calculation was conducted on the assumption that the injected gas immediately mixed and diffused uniformly in the furnace radial direction at the position of injection (perfect mixing). The results are shown in Fig. 7, from which the followings have become clear:

(1) The injection of $1 \mathrm{~kg}$ of gasified fuel oil saves about $1.1 \mathrm{~kg}$ of coke, but the replacement ratio gradually decreases with the increase of the quantity of reducing gas injected.

(2) When the temperature of reducing gas is with-

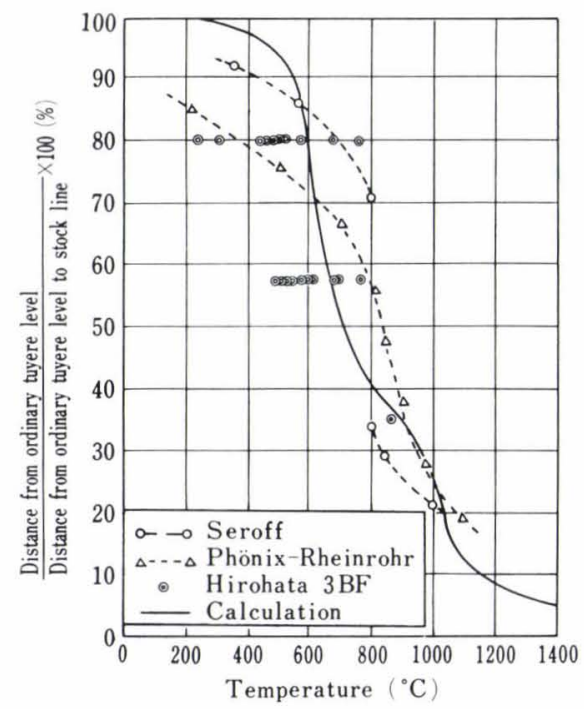

Fig. 6. Longitudinal distributions of temperature inside blast furnace

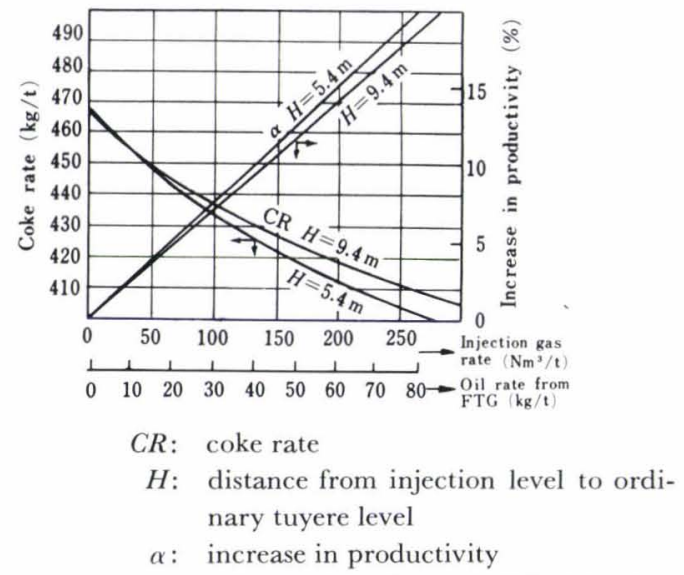

Fig. 7. Calculation results on the effect of FTG injection on blast furnace performance in a range of $1000^{\circ}$ to $1200^{\circ} \mathrm{C}$, the injecting temperature has little effect on the coke rate.

\section{Correction from the Measurement of the Gas Mixing Inside the Blast Furnace}

In the above, the reducing gas was assumed to mix uniformly with the furnace gas immediately at the injecting position. However, the effect of the actual injection will be influenced by the degree of mixing of the reducing gas inside the blast furnace.

\section{Preliminary Test with Water}

A container was packed with small glass spheres as illustrated in Fig. 8. Water was fed from the bottom and colored water was added from the side wall. The result showed that the diffusion of colored water at the injecting position was governed by the ratio between the quantity of water from the bottom and that of colored water from the side wall, and not influenced at all by the injection speed of colored water or by the size of glass spheres. This fact indicates that the injection speed is immediately diminished by the packing. Next a similar test was made by use of a tower packed with glass spheres and having a vertical channel. The colored water did not spread to the opposite side through the channel. This fact shows that the injected gas does not penetrate to the center of the furnace,

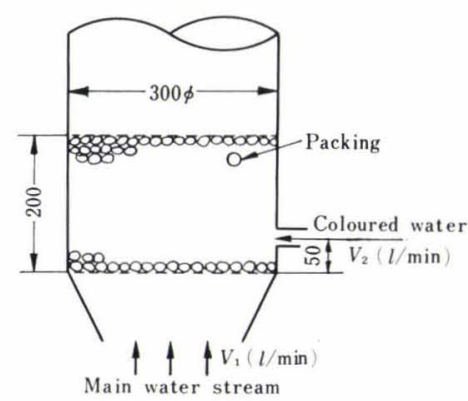

Packing: 3.5 or $6.0 \mathrm{~mm} \phi$ glass sphere

Fractional void volume: 0.33 (random packing)

Fig. 8. Experimental equipment for mixing test with water

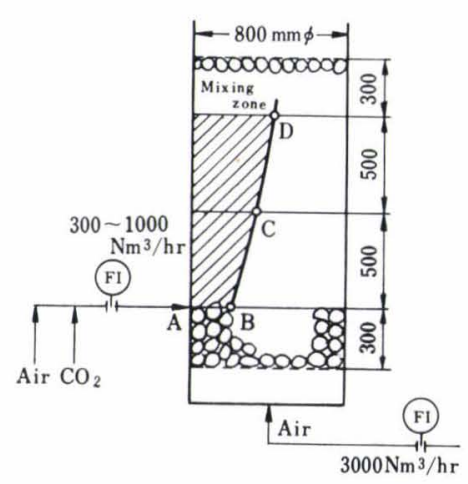

Packing: $15.5 \mathrm{~mm} \dot{\phi}$ Al-sphere

Fractional void volume: 0.37 (random packing)

Injection flow rate: $450 \mathrm{Nm}^{3} / \mathrm{hr}$

Injection velocity: $92 \mathrm{~m} / \mathrm{sec}$

Main flow rate: $3030 \mathrm{Nm}^{3} / \mathrm{hr}$

Nozzle diameter: $41.6 \mathrm{~mm} \phi$

Fig. 9. Experimental equipment for mixing test with air and $\mathrm{CO}_{2}$ and test results 
when there is a highly permeable portion around the furnace.

\section{Pilot Test with Air and $\mathrm{CO}_{2}$}

There are only few researches reported on the mixing of gases inside packing layers. ${ }^{11}$ ) So a pilot test with air and $\mathrm{CO}_{2}$ was conducted by using apparatus as shown in Fig. 9. Aluminum spheres $15.5 \mathrm{~mm}$ in diameter were packed in layers and air was blown in from the bottom of the packed tower at a superficial speed of 1.5 to $2.0 \mathrm{~m} / \mathrm{sec}$, which is corresponding to the actual superficial speed of blast furnace gas. The authors examined the mixing rate by injecting the mixture of air and $\mathrm{CO}_{2}$ from the side wall at various different injection speeds, sampling the mixed gas at various points in the packing layers and measuring the concentration of $\mathrm{CO}_{2}$ by means of a gas chromatograph. In order to check the concentration of $\mathrm{CO}_{2}$ in the mixing zone in detail, they further conducted a similar test by using apparatus as shown in Fig. 10. The some part of the results of these tests are shown in Figs. 9 and 10, respectively. In Fig. 9, point A shows the position of injecting the mixture of air and $\mathrm{CO}_{2}$ and the curve BCD the boundary line for the concentration of $\mathrm{CO}_{2}$ to become zero, the gas injected at point A spreading only within the shaded zone. In

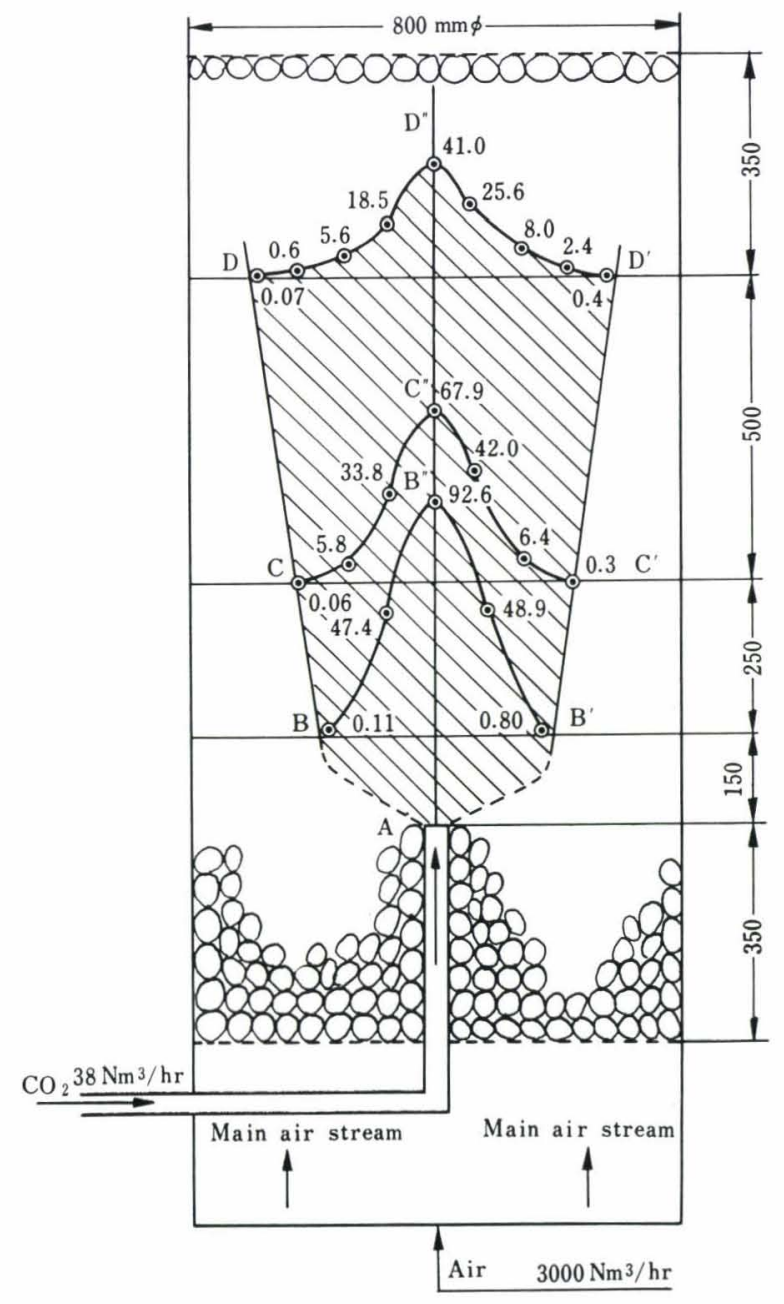

Packing: $15.5 \mathrm{~mm} \phi$ Al-sphere Gas velocity: $4 \mathrm{~m} / \mathrm{sec}$

Fig. 10. Experimental equipment for mixing test with air and $\mathrm{CO}_{2}$ and test results
Fig. 10, point A shows the position of injecting the air$\mathrm{CO}_{2}$ mixture, curves $\mathrm{ABCD}$ and $\mathrm{AB}^{\prime} \mathrm{C}^{\prime} \mathrm{D}^{\prime}$ boundary lines for the concentration of $\mathrm{CO}_{2}$ to become zero and curves $\mathrm{BB}^{\prime \prime} \mathrm{B}^{\prime}, \mathrm{CC}^{\prime \prime} \mathrm{C}^{\prime}$, and $\mathrm{DD}^{\prime \prime} \mathrm{D}^{\prime}$ distributions of $\mathrm{CO}_{2}$ concentration at the respective levels, the gas injected at point A spreading only within the shaded zone. Figures in Fig. 10, for example, 41.0 at point $\mathrm{D}^{\prime \prime}$, indicate the concentration of $\mathrm{CO}_{2}$ at the respective points. The authors confirmed the same phenomenon, as in the case of the preliminary test with water, that the injected gas immediately lost its injection speed and diffused abruptly in a circular or semi-circular shape according to the ratio of "the quantity of injected gas/the total quantity of gas in the tower." Also it was established that the mixing and diffusion of injected gas in the radial direction, while the gas was rising in the tower, took place nearly at a fixed rate, showing an angle of about $15^{\circ}$ to the vertical axis.

The diffusion of injected gas was determined in the actual furnace operation by using RI tracer and it was found that the result closely coincided with those of the model tests. For this reason, the calculated results in the previous section must be corrected. It seems that the correction factor for gas efficiency is smaller than 0.9 , by simplified calculation to sum up individual reducing rate in several concentric annular rings of cross section of the shaft.

\section{Equipment and Operating Technology}

The flow sheet of the equipment of reducing gas injection has already been shown in Fig. 4 . Since this equipment is used to handle the hot reducing gas and is also closely related to the blast furnace operation, it requires special considerations on the equipment and its operation.

As for the refractories, high-purity alumina bricks and castable refractories were employed for service because hot gas contains much $\mathrm{H}_{2}$ and $\mathrm{CO}$. The impurities in the refractories was minimized. The $\mathrm{SiO}_{2}$ in refractories will be reduced by $\mathrm{H}_{2}$ at an elevated temperature and the refractories are weared and lose strength ${ }^{12)}$ by the reaction of $\mathrm{SiO}_{2}(\mathrm{~s})+\mathrm{H}_{2}(\mathrm{~g})=\mathrm{SiO}(\mathrm{g})$ $+\mathrm{H}_{2} \mathrm{O}(\mathrm{g})$. Therefore, the $\mathrm{SiO}_{2}$ content of the refractories used in the equipment was kept below $0.1 \%$. Hot gas valves, injectors, and the gas cooler which are fabricated from metals were water-cooled or evaporative-cooled. The soot-containing gas had a high radiation heat-transfer coefficient and there existed the possibility of corrosion owing to the $\mathrm{H}_{2} \mathrm{~S}, \mathrm{H}_{2} \mathrm{O}$, and $\mathrm{H}_{2}$ contained in the gas. Also considerations were given to the prevention of changes in the ratio of fuel oil and oxygen at the burner even in case of changes in the blast furnace pressure and to the automatic safety system against the occurrence of sudden accident in the whole system including the blast furnace operation.

The effect of the injection upon the furnace condition was also examined. Especially, the permeability in the upper shaft might be decreased by the deposits of carbon due to the increase of $\mathrm{H}_{2}$ content in the gas. The reduction tests with mixtures of $\mathrm{CO}, \mathrm{H}_{2}, \mathrm{~N}_{2}, \mathrm{CO}_{2}$, and $\mathrm{H}_{2} \mathrm{O}$ at various different ratios expected in actual 
Table 2. Operation data of reducing gas generation

\begin{tabular}{l|l} 
Feed rate of heavy oil $(\mathrm{kg} / \mathrm{hr})$ & 5000
\end{tabular}

Product gas rate $\left(\mathrm{Nm}^{3} / \mathrm{hr}\right)$

Charge rate of oxygen $\left(\mathrm{Nm}^{3} / \mathrm{hr}\right)$

Charge rate of steam $(\mathrm{kg} / \mathrm{hr})$

Gas temperature in generator $\left({ }^{\circ} \mathrm{C}\right)$

Gas pressure in generator $\left(\mathrm{kg} / \mathrm{cm}^{2}-\mathrm{G}\right)$

Reducing ratio

16000

4100

800

1500

2.1

8.0

Product gas composition

$\mathrm{CO}(\%)$

43.5

$\mathrm{H}_{2}(\%)$

$\mathrm{CO}_{2}(\%)$

$\mathrm{H}_{2} \mathrm{O}(\%)$

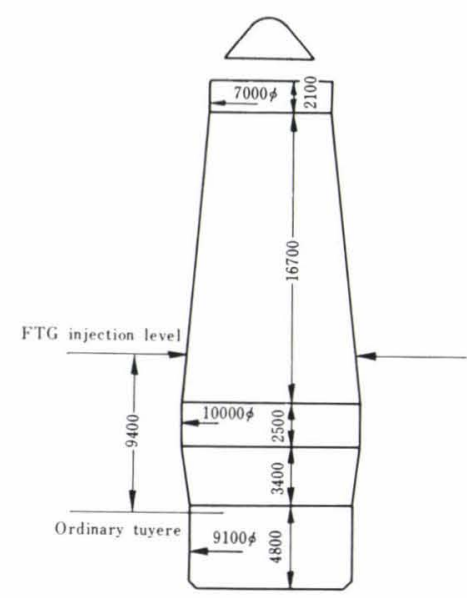

Fig. 11. Profile of Hirohata No. 3 blast furnace and level of reducing gas injection

blast furnaces were carried out by the use of ore reduction testing equipment by Gakushin method (a standard test for the reducibility test in Japan) and also the permeability resistance of the packed layer was measured using such mixed gases. The results of this measurements convinced the authors that the injection of reducing gas would not cause carbon deposits and degradation of ores, if only small amounts of $\mathrm{H}_{2} \mathrm{O}$ or $\mathrm{CO}_{2}$ were present in the injected gas.

\section{Results of Commercial-scale Test with a Blast Furnace}

After a joint research with Texaco Inc. on the application of the process to a blast furnace through the pilot plant experiment, a commercial-scale test plant have been installed, with a fuel-oil-gasifying capacity of $5 \mathrm{t} / \mathrm{hr}$ at Hirohata No. 3 blast furnace. The experiment was made with the actual blast furnace aiming at reduction of coke rate by $30 \mathrm{~kg} / \mathrm{t}$.

This process may be roughly divided into two stages.

In the first stage of the experiment (August to October 1969), the followings were investigated.

(1) Confirmation of the reducing gas generation technique on a commercial scale.

(2) Confirmation and development of the method of injecting the reducing gas into a blast furnace,
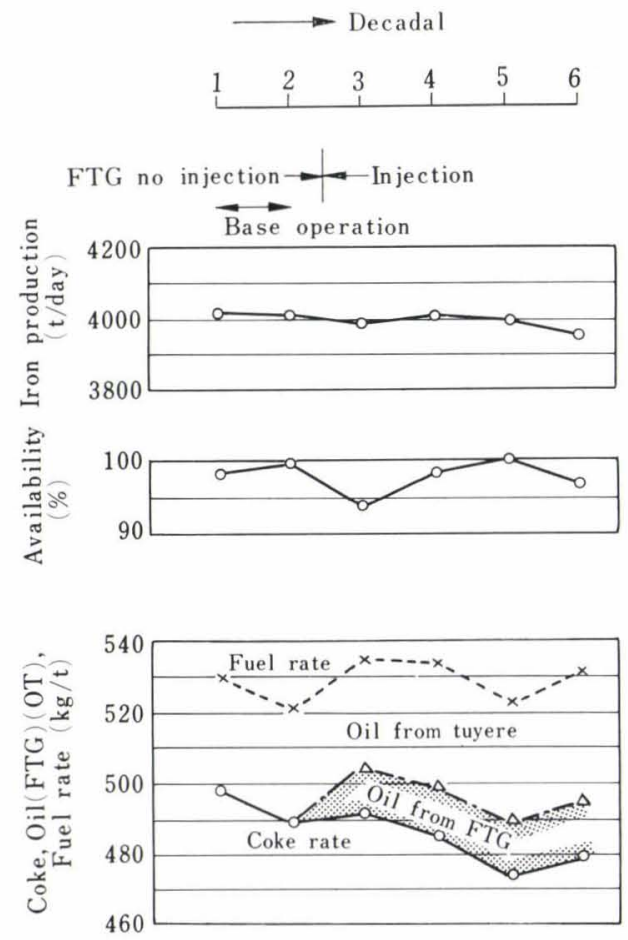

Fig. 12. Results of the blast furnace operation in Test 1 (data: decadal)

namely, confirmation of stable injection against changes in the furnace condition and establishment of the method of injection to meet the blast furnace operation.

(3) Confirmation of the equipment performance.

The objectives were generally accomplished but some problems remained unsolved in the gas generation, the generation of soot in particular. So improvement of the gas generating technique was pushed forward.

In the second stage (January 1970 to March 1971), the following items were investigated.

(1) Confirmation of the effect of reducing gas injection on coke rate.

(2) Confirmation of the influence on furnace condition.

(3) Confirmation of the long-period operational performance of the whole equipment.

\section{Results of Reducing Gas Generating Test}

The operating conditions of reducing gas generation are shown in Table 2. Reducing gas suitable for use in a blast furnace are with a high $R$ value and with little soot, and thus, reducing gas having an $R$ value of six to eight may be considered as fairly good at the present.

2. Results of Test of Reducing Gas Injection into Blast Furnace

1. Outline of the Test Procedure of Reducing Gas Injection into Blast Furnace

The reducing gas, according to the model of equational analysis, is best injected at as low a position in the blast furnace as possible for higher effect. However if the position is so low as to reach the softening 


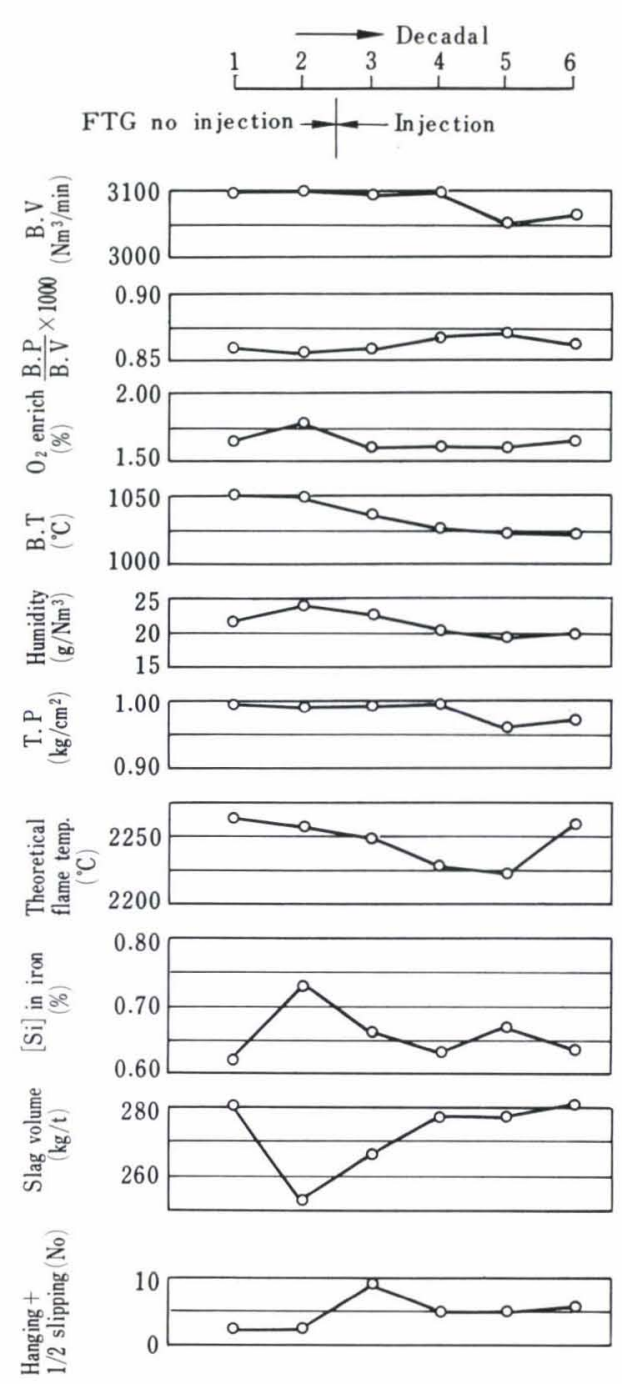

B.P: blast pressure $\left(\mathrm{kg} / \mathrm{cm}^{2}\right)$

B.V: blast volume $\left(\mathrm{Nm}^{3} / \mathrm{min}\right)$

B.T: blast temperature $\left({ }^{\circ} \mathrm{C}\right)$

T.P: top pressure $\left(\mathrm{kg} / \mathrm{cm}^{2}-\mathrm{G}\right)$

Fig. 13. Conditions of the blast furnace operation in Test 1 (data: decadal)

and melting zone of the furnace burden, it becomes difficult to obtain uniform pressure and flow of injected reducing gas from four places. So the authors injected the gas through the four injectors equipped at the lower part of the shaft about $9.4 \mathrm{~m}$ above the usual tuyeres. This position was estimated to be theoretically most effective in consideration of the operating environment and also the layout of injecting equipment. Figure 11 shows the profile of Hirohata No. 3 blast furnace and the reducing gas injecting positions.

From January to August 1970, they operated the test plant at about $50 \%$ of the full capacity of reducinggas-generator to master the operating technique and to observe the blast furnace condition (Test 1). During the three months from December 1970 to March 1971, they conducted Test 2 by operating the generator at more than $90 \%$ of its designed capacity, namely, injecting the reducing gas obtained by cracking fuel oil at a rate of $30 \mathrm{~kg} / \mathrm{t}$ of pig iron.

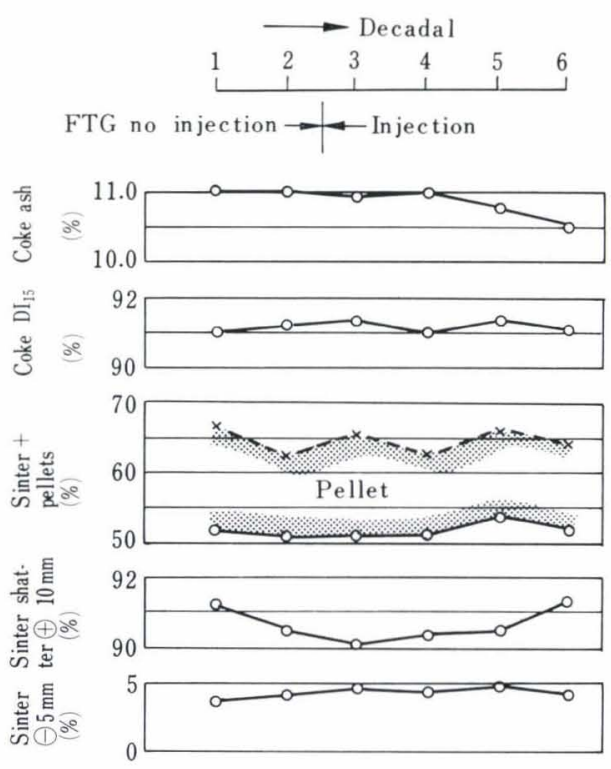

Fig. 14. Conditions of the burden in Test 1 (data: decadal)
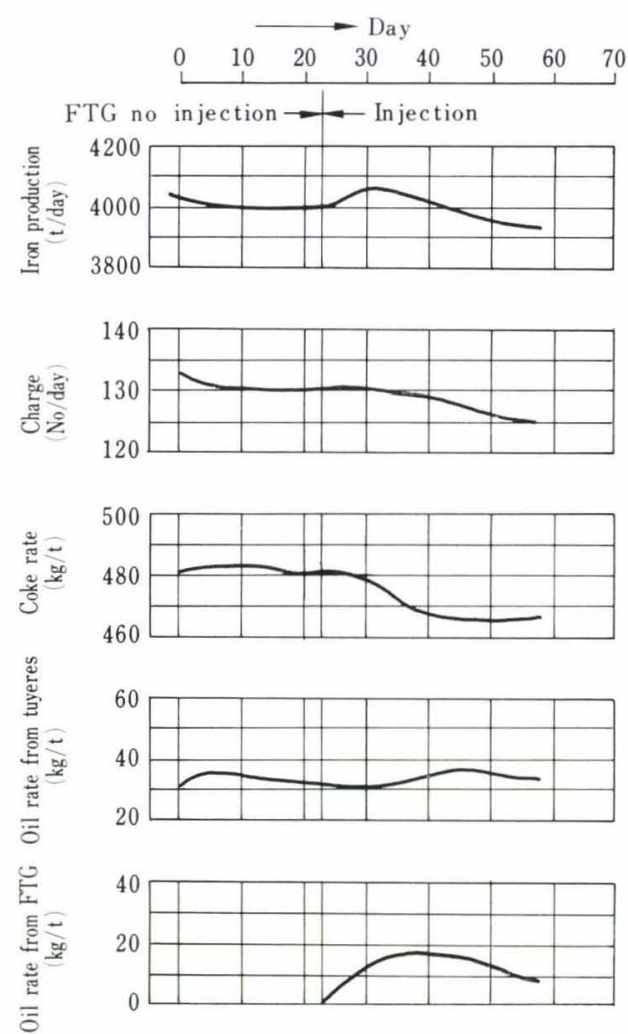

Fig. 15. Results of the blast furnace operation in Test 1 (data: daily)

\section{Results of Test Operation by Injecting $30 \mathrm{~kg} / \mathrm{t}$ of Fuel Oil through the Tuyeres and $15 \mathrm{~kg} / \mathrm{t}$ of Fuel Oil by the FTG Process (Test 1)}

At first, they took a cautious attitude and injected the gas through two injectors at about $50 \%$ of the gasifying capacity in order to avoid unexpected changes in heat level and other conditions in the operation of the actual blast furnace.

As for the results before and after the gas injection, Fig. 12 shows the results of blast furnace operation, Fig. 13 the blast furnace operating conditions, Fig. 14 


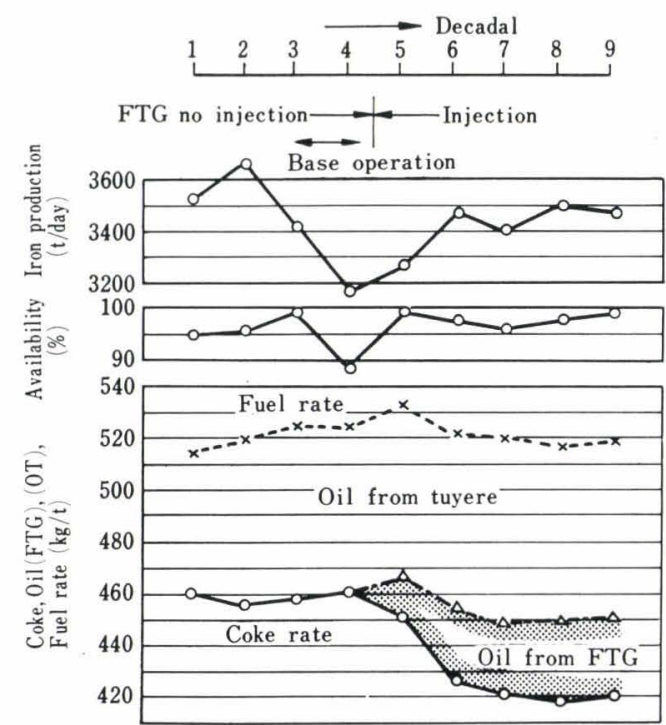

Fig. 16. Results of the blast furnace operation in Test 2 (data: decadal)

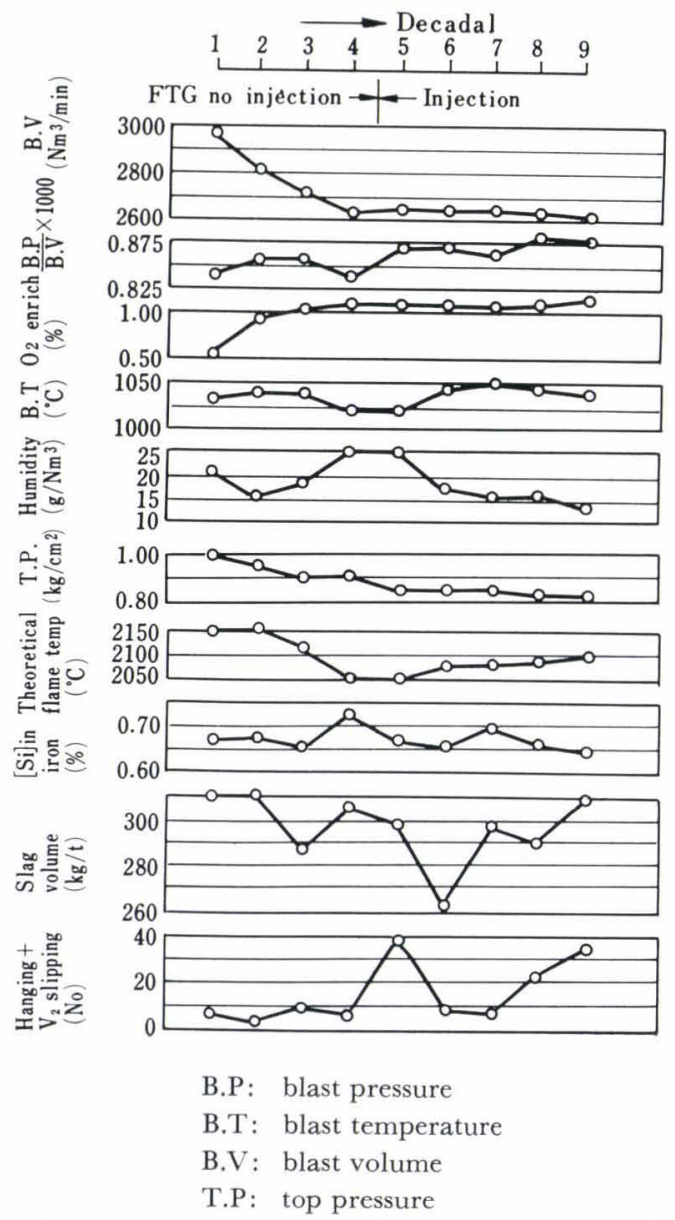

Fig. 17. Conditions of the blast furnace operation in Test 2 (data: decadal)

the burden conditions for every ten days, and Fig. 15 the day-by-day changes in the blast furnace operation results.

During this test period the plant was operated at a blast volume of 3050 to $3100 \mathrm{Nm}^{3} / \mathrm{min}$ (iron productivity 2.2 to $2.3 \mathrm{t} / \mathrm{m}^{3}$ /day) or near the full capacity. The blast furnace was operated with special care so

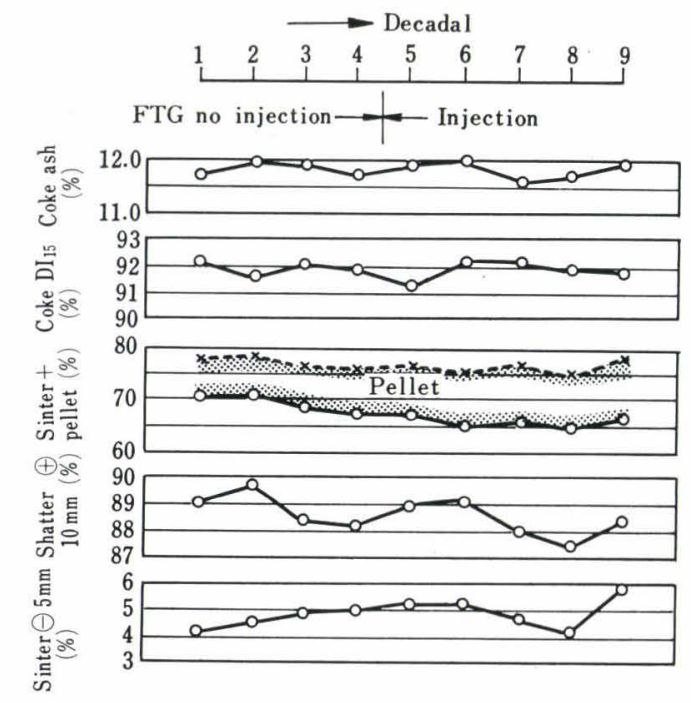

Fig. 18. Conditions of the burden in Test 2 (data: decadal)
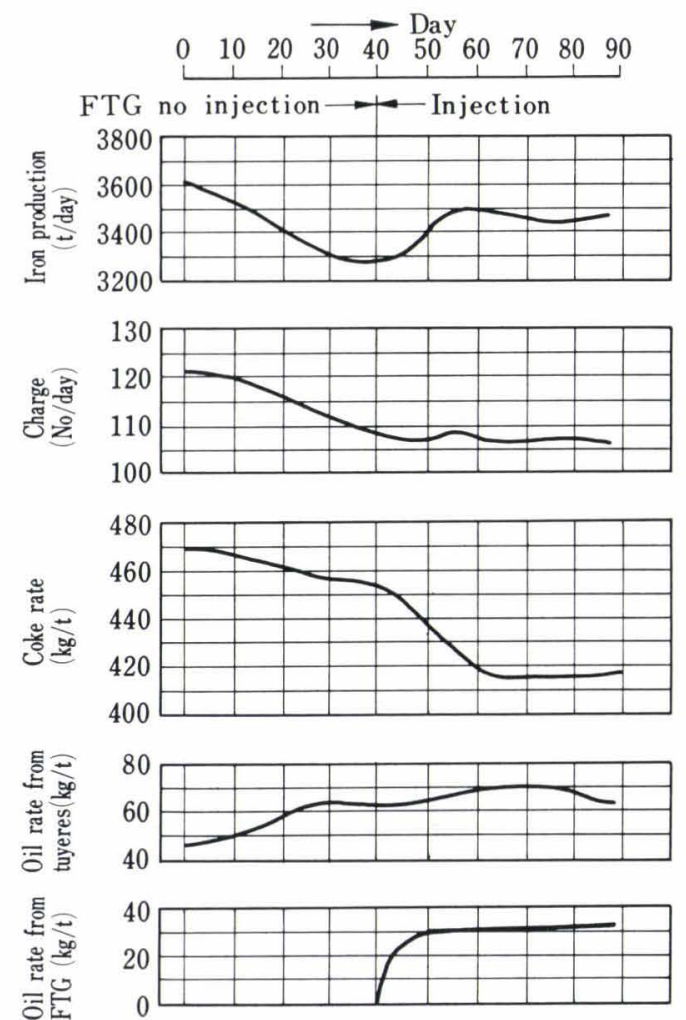

Fig. 19. Results of the blast furnace operation in Test 2 (data: daily)

that the blast volume, top pressure, quantity of enriched oxygen, and burden condition would be as stable as possible.

(1) The furnace condition remained relatively favorable after the reducing gas was injected. Though slips somewhat increased, changes in the silicon content of iron were small.

(2) The quantity of fuel oil injection by the FTG process was only $15 \mathrm{~kg} / \mathrm{t}$, but it was possible to lower the coke rate almost proportional to the gas injection. When the test operation was compared with the reference operation by correcting the operating conditions (blast temperature, blast humidity, ash content of 
Table 3. Operation data of blast furnace

\begin{tabular}{|c|c|c|c|c|}
\hline \multirow{2}{*}{ Item } & \multicolumn{2}{|c|}{ Test 1} & \multicolumn{2}{|c|}{ Test 2} \\
\hline & Base & Gas injection & Base & Gas injection \\
\hline Iron production (t/day) & 3970 & 4045 & 3272 & 3442 \\
\hline Coke rate $(\mathrm{kg} / \mathrm{t})$ & 486.3 & 477.0 & 460.4 & 419.3 \\
\hline Oil rate from tuyere $(\mathrm{kg} / \mathrm{t})$ & 34.7 & 32.1 & 60.0 & 67.5 \\
\hline Fuel rate $(\mathrm{kg} / \mathrm{t})$ & 521.0 & 509.1 & 520.4 & 486.8 \\
\hline Oil rate from FTG $(\mathrm{kg} / \mathrm{t})$ & 0 & 13.5 & 0 & 29.6 \\
\hline Total fuel rate $(\mathrm{kg} / \mathrm{t})$ & 521.0 & 522.6 & 520.4 & 516.8 \\
\hline Blast volume $\left(\mathrm{Nm}^{3} / \mathrm{min}\right)$ & 3100 & 3076 & 2676 & 2638 \\
\hline Oxygen enrichment $\left(\mathrm{Nm}^{3} / \mathrm{min}\right)$ & 67.8 & 64.1 & 36.2 & 36.7 \\
\hline Blast temperature $\left({ }^{\circ} \mathrm{C}\right)$ & 1046 & 1024 & 1034 & 1046 \\
\hline Humidity $\left(\mathrm{g} / \mathrm{Nm}^{3}\right)$ & 20.0 & 17.9 & 22.3 & 16.0 \\
\hline [Si] content in iron $(\%)$ & 0.65 & 0.65 & 0.70 & 0.68 \\
\hline Sinter + pellets $(\%)$ & 64.5 & 65.9 & 69.9 & 70.1 \\
\hline Coke ash (\%) & 10.7 & 10.7 & 11.8 & 11.6 \\
\hline
\end{tabular}

coke, slag volume, silicon content of iron, and agglomerated ore ratio), the replacement ratio of coke by oil was about 1.0.

(3) As the plant was operated at about $50 \%$ of its full gasifying capacity, the injection of reducing gas was carried out through two opposing injectors. The injection at such places could not be said perfect in respect of uniformity in the shaft cross-section but did not cause any unfavorable gas flow to affect the blast furnace operation.

\section{Results of Test Operation by Injecting $70 \mathrm{~kg} / \mathrm{t}$ of Fuel} Oil from the Tuyeres and $30 \mathrm{~kg} / \mathrm{t}$ of Fuel Oil by the FTG Process (Test 2)

Test 2 was carried out in order to confirm the effect of reducing gas injected as additional fuel when the quantity of fuel oil injected from the tuyeres approached its limit. The blast furnace was operated with FTG oil injection as high as $90 \%$ of the gasifying capacity and at $70 \mathrm{~kg} / \mathrm{t}$ of fuel oil injection from the tuyeres. In this case, four reducing gas injectors were utilized. As in the case of Test 1, conditions of furnace operation and burden were made as stable as possible.

As for the results before and after the gas injection, Fig. 16 shows the results of blast furnace operation, Fig. 17 the blast furnace operating conditions, Fig. 18 the burden conditions for every ten days, and Fig. 19 the day-by-day changes in the blast furnace operation results.

(1) Hanging and slipping occurred for a short time because the blast volume and the burden condition were changed during the test period. However, the furnace condition remained favorable in general.

(2) The effect of reducing gas injection upon coke rate was tested at $30 \mathrm{~kg} / \mathrm{t}$ of fuel oil injection by the FTG process. The decrease of coke rate corresponding to this was measured. The coke rate became about $420 \mathrm{~kg} / \mathrm{t}$, and the replacement ratio of coke by oil from the FTG process was about 0.9 .

(3) To investigate the mixing of reducing gas with

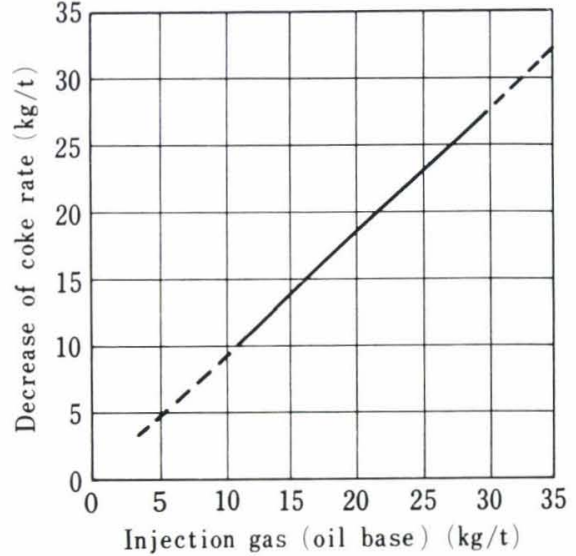

Fig. 20. Effects of reducing gas injection on coke rate

the blast furnace gas, a test was made by using RI tracer. The result was that the condition of diffusion was similar to those obtained from the model tests of mixing and diffusion by water, air and carbon dioxide. The utilization rate of $\mathrm{H}_{2}$ in the reducing gas at that time was within 40 to $60 \%$.

(4) The reducing gas was injected through four diagonally opposed injectors at about $90 \%$ of the oil gasifying capacity of the generator. The furnace heat level could be controlled better than was expected. Changes in the silicon content of iron and other conditions proved not much different from those of ordinary operation.

\section{Discussions}

(1) Coke-saving and Iron Production

Table 3 shows the operational data of the blast furnace obtained from the tests with oil injections of 15 and $30 \mathrm{~kg} / \mathrm{t}$ by the FTG process. Figure 20 shows the relationship between the quantity of reducing gas injected and the decrease in coke rate after correction of operating conditions. Reduction in coke per kilogram of fuel oil was 0.9 to $1.0 \mathrm{~kg}$ within a range up to $70 \mathrm{~kg} / \mathrm{t}$ of oil injection from the tuyeres and up 
to $30 \mathrm{~kg} / \mathrm{t}$ of oil injection by the FTG process. This coincided with the result of theoretical analysis by the equational analysis with correction for the gas mixing. On the other hand, iron production did not increase so much despite the remarkable decrease of coke rate perhaps because the number of charges decreased due to the decrease of carbon solution. The rate of increase of iron production was about $1 / 2$ to $1 / 3$ of rate expected from the rate of decrease of coke rate.

\section{(2) Operational Response}

As for the response of the furnace heat level to reducing gas injection, it took about one week after the injection to obtain the desired ore/coke ratio (ratio between the quantity of ore charged and that of coke charged). Its response appeared slower than that of the increase or decrease of ore charge per fixed quantity of coke charged. Therefore, the silicon content of iron showed a gradual change and it was easy to control the furnace operation.

If the response to gas injection is measured in terms of coke rate, the effect began to appear after about one week and a steady state is obtained after about fifteen days as shown in Figs. 15 and 19. The authors are still investigating the reason for this slow response. The distributions of burden and gases in the furnace after reducing gas injection or the rise of temperature in the shaft may be considered to account for this phenomena.

(3) Injector

The gas was injected through four injectors in the furnace shaft. In some cases the injectors required boring before injection as they were clogged by deposited materials. But once the injection was started, there occurred no such trouble and the injection of reducing gas continued smoothly. If injection is made through lower parts of the shaft in the future, the use of a boring machine shall be necessary during the operation.

\section{Conclusion}

As a new method of solving the problem of coking coal shortage, the authors tested the injection of reducing gas into the blast furnace and confirmed that its results were almost as expected. In this paper they have described a commercial method of production of the reducing gas, the estimation of the effects of injection of reducing gas upon blast furnace performance by mathematical models, and the phenomenal aspect during actual operation. The results of the experiments to date are summarized below:

(1) The partial oxidation process was adopted to produce the reducing gas in order to obtain hot gas having a high reducing power from heavy oil.

(2) The claculation of the effect of reducing gas injection by the equational analysis of blast furnace clarified the following facts:

(i) About $1.1 \mathrm{~kg}$ of coke can be saved per kilogram of oil, but the replacement ratio gradually decreases with the increase of the volume of injection. (ii) The injecting positions must preferably be at about $9.4 \mathrm{~m}$ or less above the tuyeres.

(iii) When the injection temperature is within a range of $1000^{\circ}$ to $1200^{\circ} \mathrm{C}$, it scarcely influences the coke rate.

(3) The injected gas diffuses at an angle of about $15^{\circ}$ and the gas efficiency is estimated below 0.9 of the theoretical value.

(4) Special consideration was given to the test plant and its operation, because the hot reducing gas had to be handled and the operation of blast furnace was closely related to its operation. However, no major problem was encountered.

(5) Concerning the effect of reducing gas injection upon the coke rate and others in the actual blast furnace:

(i) About 0.9 to $1.0 \mathrm{~kg}$ of coke was saved per kilogram of heavy oil. This result agreed comparatively well with the result of theoretical analysis.

(ii) The reducing gas injection had very little unfavorable effect on the furnace condition, and the furnace remained comparatively stable.

(iii) The response to reducing gas injection was exceedingly slow, and it took about 10 to 15 days to reach a steady state. Theoretical explanation of this slowness is now under study.

\section{Acknowledgements}

The authors wish to express their sincere thanks to Dr. Shozo Watanabe, Director of Products Research \& Development Laboratories, Dr. Kiyoaki Hisada, exDeputy Director of the same, and Mr. Keiichi Wakabayashi of Technical Development Department all of Nippon Steel Corporation and to President Paull, Dr. Marion, and others of Texaco Development Corporation for their kind guidance and cooperation in preparing this paper.

\section{REFERENCES}

1) K. Kodama, S. Otsubo, A. Shigemi, and T. Ogata: Tetsuto-Hagané, 48 (1962), 1221.

2) R. Laurent: O.P.D. Report, No. 196/63 M, June (1963), 27.

3) N. B. Melcher, R. B. Schulter, T. L. Joseph, and R. J. Leary: Ironmaking Proceeding, Trans. AIME, 27 (1968), 151.

4) T. Miyashita, H. Nishio, T. Shimozuma, T. Yamada, and M. Otsuki: Tetsu-to-Hagané, 58 (1972), 608.

5) I. Muchi, J. Yagi, K. Tamura, and A. Moriyama: Nippon Kinzoku Gakkaishi, 30 (1966), 826.

6) I. Muchi, K. Tamura, J. Yagi, and A. Moriyama: Nippon Kinzoku Gakkaishi, 30 (1966), 1109.

7) I. Muchi, K. Tamura, J. Yagi, and A. Moriyama: Nippon Kinzoku Gakkaishi, 30 (1966), 1115.

8) C. J. Fielden and B. I. Wood: JISI, 206 (1968), 650.

9) G. V. Korshikov: Izv. Akad. Nauk SSSR, 4 (1965), 8.

10) E. Schürmann and W. Zischkale: S'ahl u. Eisen, 80 (1960), 854.

11) M. Suzuki: Kagaku Kogaku, 29 (1965), No. 4, 253.

12) M. S. Crowley: Ceramic Bulletin, 46 (1967), 7. 